\title{
The effect of the orexins on food intake: comparison with neuropeptide $Y$, melanin-concentrating hormone and galanin
}

\author{
C M B Edwards, S Abusnana, D Sunter, K G Murphy, M A Ghatei and S R Bloom \\ ICSM Endocrine Unit, Hammersmith Hospital, London W12 0NN, UK \\ (Requests for offprints should be addressed to S R Bloom)
}

\begin{abstract}
Orexin-A and orexin-B (the hypocretins) are recently described neuropeptides suggested to have a physiological role in the regulation of food intake in the rat. We compared the orexigenic effect of the orexins administered intracerebroventricular (ICV) with other known stimulants of food intake, one strong, neuropeptide Y (NPY), and two weaker, melanin-concentrating hormone $(\mathrm{MCH})$ and galanin. Orexin-A consistently stimulated food intake, but orexin-B only on occasions. Both peptides stimulated food intake significantly less than NPY, but to a similar extent to $\mathrm{MCH}$ ( $2 \mathrm{~h}$ food intake: NPY $3 \mathrm{nmol}, 7.2 \pm 0.9 \mathrm{~g}$ vs saline, $1.5 \pm 0.2 \mathrm{~g}, P<0.001$, MCH 3 nmol, $3.2 \pm 0.8 \mathrm{~g}$ vs saline, $P<0.01$, orexin-B $30 \mathrm{nmol}, 2.6 \pm 0.5$
\end{abstract}

\section{Introduction}

Originally reported as the hypocretins, due to their hypothalamic location and sequence homology to secretin, two novel peptides have been demonstrated to be present in neuronal cell bodies of the dorsal and lateral hypothalamus, with fibres projecting to multiple targets including the brain stem (De Lecea et al. 1998). Later identified and named as orexin-A and orexin-B, these same peptides were reported to powerfully stimulate feeding (Sakurai et al. 1998), $3 \mathrm{nmol}$ orexin-B stimulating $2 \mathrm{~h}$ food intake 5 -fold and the same dose of orexin-A stimulating 6-fold over saline control. The genetic precursor to both peptides, prepro-orexin, was shown to be upregulated 2.4-fold after a $48 \mathrm{~h}$ fast, greater than the upregulation of NPY mRNA under the same experimental conditions. Two receptors for the peptides, $\mathrm{OX}_{1}$ and $\mathrm{OX}_{2}$ were expressed exclusively in the brain, though to date the distribution of the receptors has not been reported. Such evidence led the authors to suggest the orexins as mediators in the central feedback mechanisms that regulate feeding behaviour (Sakurai et al. 1998).

We have used orexin-A, and orexin-B from two separate sources, to compare their effects with more established orexigenic agents. We also assessed the effect of orexin-A on the induction of the immediate early gene $c$-fos, a marker of neuronal activation (Sagar et al. 1988). Finally, we investigated whether the orexins act through the $\mathrm{g}$ vs saline, $P=0.11$ ) and to galanin ( $1 \mathrm{~h}$ food intake: galanin 3 nmol, $2.0 \pm 0.4 \mathrm{~g}$ vs saline, $0.8 \pm 0.2 \mathrm{~g}, P<0.05$, orexin-A 3 nmol, $2.2 \pm 0.4 \mathrm{~g}$ vs saline, $P=0.01 ; 2$ hour food intake: orexinB $3 \mathrm{nmol}, 2.4 \pm 0.3 \mathrm{~g}$ vs saline, $1.3 \pm 0.2 \mathrm{~g}, P<0.05)$. Following ICV orexin-A, hypothalamic $c$-fos, a marker of neuronal activation, was highly expressed in the paraventricular nucleus (PVN), and the arcuate nucleus ( $P<0.005$ for both). IntraPVN injection of orexin-A stimulated $2 \mathrm{~h}$ food intake by one gram (orexin-A $0.03 \mathrm{nmol}, 1.6 \pm 0.3 \mathrm{~g}$ vs saline, $0.5 \pm 0.3 \mathrm{~g}$, $P<0.005)$. These findings support the suggestion that the orexins stimulate food intake. However, this effect is weak and may cast doubt upon their physiological importance in appetite regulation in the rat. paraventricular nucleus (PVN), by injecting directly into the nucleus.

\section{Materials and Methods}

Peptides

Orexin-A and orexin-B were purchased from Pheonix Pharm. Inc., Mountain View, CA, USA. NPY, MCH, galanin and orexin-B were synthesised using fmoc chemistry on an Advanced ChemTech 396MPS peptide synthesiser. The products comprised one major peak which was purified to homogeneity by reversed phase HPLC on a C8 column (Phenomenex, Macclesfield, UK) using a gradient of acetonitrile in $0.1 \%$ trifluoroacetic acid. Electrospray and MALDI-TOF mass spectrometry was used to confirm the peptides identity.

\section{Animals}

Adult male Wistar rats (250-300 g) were maintained under controlled conditions of temperature $\left(21-23^{\circ} \mathrm{C}\right)$ and light $(12 \mathrm{~h}$ light, $12 \mathrm{~h}$ dark) with ad libitum access to food (RM1 diet, SDS UK Ltd) and water. All animals were handled daily from recovery after surgery to the time of study. In the case of the $c$ fos studies, the animals were each handled for ten minutes daily for ten days to minimise stress, which readily activates $c$ fos (Arnold et al. 1992). 


\section{Cannulation}

For the intracerebroventricular (ICV) studies, animals were implanted with permanent 22-gauge stainless steel cannulae projecting to the third ventricle and peptides were administered as previously described (O'Shea et al. 1997). The correct position of the cannula (>90\%) was confirmed by a positive dipsogenic response to angiotensin II.

For $c$-fos studies, animals were implanted with permanent 23-gauge stainless steel cannulae projecting to the lateral ventricle and peptides were administered as previously described (Lambert et al. 1995).

For PVN studies, rats were anaesthetized with xylazine (20 $\mathrm{mg} / \mathrm{kg}$ ) (Rompun, Bayer, Suffolk, UK) and ketamine (100 mg/ $\mathrm{kg}$ ) (Ketalar, Parke Davis, Pontypool, Gwent, UK). Permanent 26-gauge stainless steel cannulae (Plastics One inc., Roanoke, VA, USA) were placed $1.8 \mathrm{~mm}$ posterior to the bregma, 0.5 $\mathrm{mm}$ lateral to the midline and implanted $7 \mathrm{~mm}$ below the outer surface of the skull. The incisor bar was set at $3 \mathrm{~mm}$ below the interaural line. This positioned the tip of the cannula approximately $1 \mathrm{~mm}$ above the PVN.

PVN injections were administered via a stainless steel injector placed in and projecting $1 \mathrm{~mm}$ below the tip of the cannula directly into the PVN. Injections were given in a volume of $1 \mu 1$ saline over 60 seconds. $25 \mathrm{nmol}$ noradrenaline, which gives a robust orexigenic response when injected intraPVN (IPVN), was administered to confirm correct cannula position (McMahon et al. 1998). Only animals (>80 \%) which ate $>2 \mathrm{~g}$ in the following $1 \mathrm{~h}$ were studied. Animals were randomised into groups prior to each study, such that the average food intake in response to noradrenaline, as well as average body weight was equal in each group.

All studies were carried out between 0900 and 1100 during the normal resting/light period when rats eat little.

\section{Experimental protocols}

Study 1 Comparative effect of orexins administered ICV with established orexigenic agents

Study la Comparative effect of orexin-B administered ICV with other orexigenic agents in the early light phase

Animals were injected with orexin-B at a dose of 10 or 30 $\mathrm{nmol}, \mathrm{MCH}$ or NPY at doses of $3 \mathrm{nmol}$ (doses greater than previously shown to stimulate food intake (Rossi et al. 1998, O'Shea et al. 1997)), or saline control ( $n=8-11$ per group). Food intake was measured 2 and $4 \mathrm{~h}$ after injection.

Study $1 b$ Comparative effect of orexin-A and orexin-B administered ICV with other orexigenic agents in the early light phase

Animals were injected with orexin-A, orexin-B, NPY or galanin at a dose of $3 \mathrm{nmol}$ (a dose previously shown to stimulate food intake (O'Shea et al. 1997)) or saline ( $n=8-12$ per group). Food intake was measured 1,2 , and $4 \mathrm{~h}$ after injection.
Study 2 Effect of orexin-A on c-fos expression

Animals were injected with orexin-A at a dose of $3 \mathrm{nmol}$ or saline control ( $n=3-4$ per group), and returned to their cages for one hour without access to food.

Study 3 Effect of IPVN orexin-A and NPY on food intake in the early light phase

Animals were injected with NPY at a dose of $0.3 \mathrm{nmol}$ or saline control ( $n=12-13$ per group). Food intake was measured $2 \mathrm{~h}$ after injection. One week later animals were injected with orexin-A at doses of 0.03 and $0.3 \mathrm{nmol}$ or saline $(n=15-16$ per group). Food intake was measured 2 and $4 \mathrm{~h}$ after injection.

Three days following the PVN studies each rat was injected with $0.5 \mu \mathrm{l}$ blue dye and killed by decapitation. The brain was removed, mounted, frozen in liquid nitrogen-cooled isopentane and stored at $-70^{\circ} \mathrm{C}$. $15 \mu \mathrm{m}$ sections were taken through the hypothalamus at $-18^{\circ} \mathrm{C}$ on a cryostat (Bright Instrument Company Ltd, UK), fixed in $0.5 \%$ acetic acid, dehydrated, stained with cresyl violet, and coverslipped prior to light microscopy examination. Data from animals in which the cannula was not found by two independent blinded investigators to be within the PVN $(<20 \%)$ were not included in the statistical analysis.

\section{Immunocytochemistry}

The protocol for $c$-fos measurement was similar to previously described (Lambert et al. 1995, Turton et al. 1996). In brief, rats were anaesthetised and perfused transcardially with $0.1 \mathrm{M}$ PBS followed by $4 \%$ paraformaldehyde. The brains were removed, fixed in $4 \%$ paraformaldehyde for four hours, and soaked overnight in $15 \%$ sucrose solution. $40 \mu \mathrm{m}$ coronal sections were cut on a freezing microtome and stained for $c$ fos-like peptide by the avidin-biotin-peroxidase method. The sections were incubated for $48 \mathrm{~h}$ in primary antibody $(1: 15,000$ in TBS (12 g Trizma base in 1 litre saline), $0.3 \%$ Triton- $X$ and $5 \%$ milk powder) at $4{ }^{\circ} \mathrm{C}$. Milk powder was used to reduce nonspecific background, as previously described (Tacha et al. 1992). The primary rabbit polyclonal antibody was purchased from Oncogene Research Products, (Cambridge, MA, USA). Sections were washed in 5\% milk powder in TBS, incubated in secondary antibody (goat anti-rabbit serum, 1:200), rewashed and processed using the Vecastain ABC kit (Vector labs). They were incubated for 3-10 mins in $1 \mathrm{mg} / \mathrm{ml}$ diaminobenzidine tetrahydrochloride (dissolved in TBS with $0.02 \%$ hydrogen peroxide added), mounted on gelatine-coated slides, left overnight to dry, dehydrated and coverslipped.

\section{Quantification}

Brain slices were examined for $c$-fos positive nuclei using light microscopy. There was no difference between the effects of orexin-A or saline except in the areas of the PVN and arcuate nuclei of the hypothalamus and the ventromedial hypothalamus (VMH). The numbers of $c$-fos positive nuclei in these 


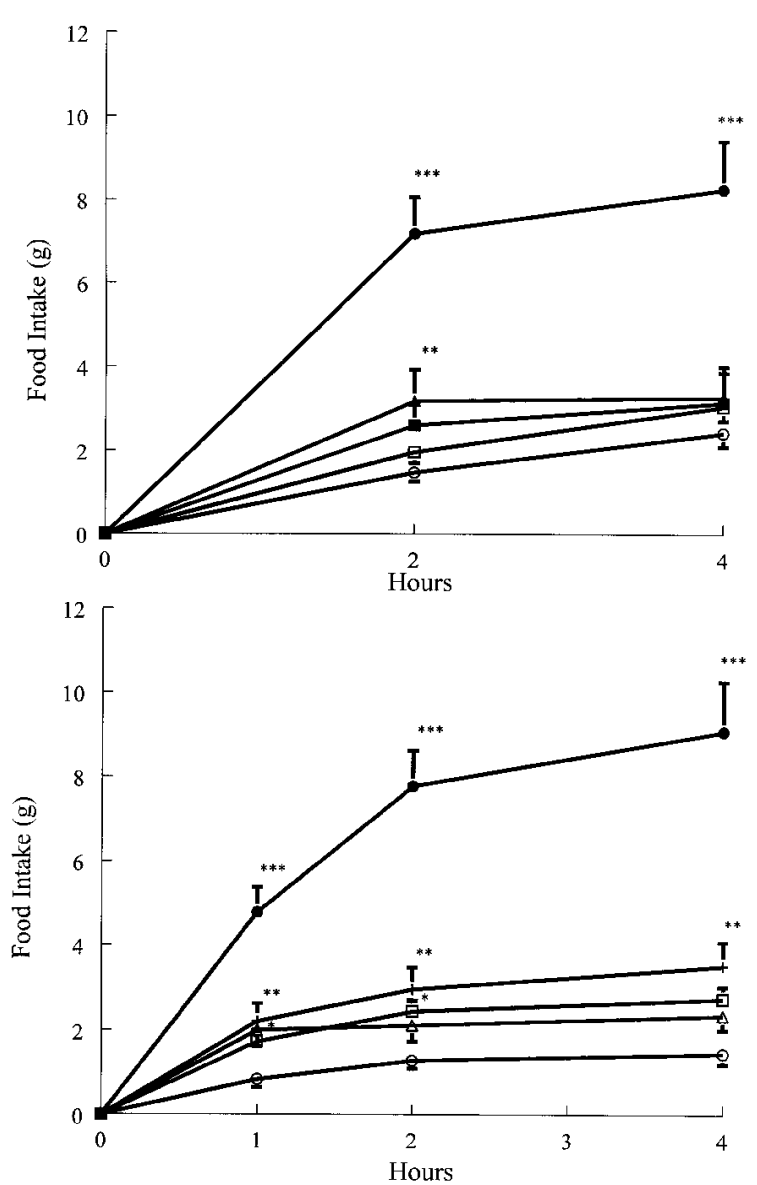

Figure $1 \mathrm{Effect}$ of different peptides on food intake when administered ICV to Wistar rats in the early light phase. Upper panel, 3nmol NPY(solid circles), 3nmol MCH (solid triangle), 10 $\mathrm{nmol}$ orexin-B (open square), $30 \mathrm{nmol}$ orexin-B (solid square) and saline control (open circle). $n=8-11$ per group. Lower panel, $3 \mathrm{nmol}$ NPY (solid circle), $3 \mathrm{nmol}$ galanin (open triangle), $3 \mathrm{nmol}$ orexin-A (+), $3 \mathrm{nmol}$ orexin-B (open square). $n=8-12$ per group. ${ }^{*} P<0.05,{ }^{* *} P<0.01,{ }^{* * *} P<0.001$ vs saline.

areas were counted using a Mackintosh-based image analysis system (Image, NIH). Numbers were counted on each section that contained any part of the nucleus of interest in a blinded manner, an average number of $c$-fos positive nuclei per section was calculated, and expressed as an integer for each animal.

\section{Statistics}

Food intake data are expressed as means \pm S.E.M.. Comparisons between groups were made by ANOVA with post hoc LSD tests. $c$-fos data are expressed as mean of the animals studied \pm S.E.M., normality of data was assessed using Mann-Whitney Rank Sum test, and data compared by unpaired t-test, using Sigmastat 2.0. Differences were considered significant at $P<0.05$.

\section{Results}

Study la Comparative effect of orexin-B administered ICV with other orexigenic agents in the early light phase

NPY significantly increased food intake at 2 and $4 \mathrm{~h}$ compared with control ( $2 \mathrm{~h}$ food intake: NPY $3 \mathrm{nmol}, 7.2 \pm 0.9 \mathrm{~g}$ vs saline, $1.5 \pm 0.2 \mathrm{~g}, P<0.001$ )(Fig. 1, upper panel). MCH also increased food intake at $2 \mathrm{~h}$ (MCH $3 \mathrm{nmol}, 3.2 \pm 0.8 \mathrm{~g}$ vs saline, $1.5 \pm 0.2 \mathrm{~g}$, $P<0.01)$. Orexin-B tended to increase food intake, however, this effect was not statistically significant (e.g. $2 \mathrm{~h}$ food intake: Orexin-B $30 \mathrm{nmol}, 2.6 \pm 0.5 \mathrm{~g}$ vs saline, $1.5 \pm 0.2 \mathrm{~g}, P=0.11$ ). NPY stimulated food intake greater than both orexin-B and MCH (NPY $3 \mathrm{nmol}, 7.2 \pm 0.9 \mathrm{~g}$ vs orexin-B $30 \mathrm{nmol}, 2.6 \pm 0.5 \mathrm{~g}$, $P<0.001$, vs $\mathrm{MCH} 3 \mathrm{nmol}, 3.2 \pm 0.8 \mathrm{~g}, P<0.001)$. Although $\mathrm{MCH}$ appeared to stimulate food intake greater than both doses of orexin- $\mathrm{B}$, this was not statistically significant $(2 \mathrm{~h}$ food intake: MCH $3 \mathrm{nmol}, 3.2 \pm 0.8 \mathrm{~g}$ vs orexin-B $10 \mathrm{nmol}, 2.0 \pm 0.3$ $\mathrm{g}, P=0.09)$.

Study $1 b$ Comparative effect of orexin-A and orexin- $B$ administered ICV with other orexigenic agents in the early light phase

NPY significantly increased food intake at 1,2 and $4 \mathrm{~h}$ compared with control ( $2 \mathrm{~h}$ food intake: NPY $3 \mathrm{nmol}, 7.8 \pm 0.8$ g vs saline, $1.3 \pm 0.2 \mathrm{~g}, P<0.001$ ) (Fig. 1, lower panel). Galanin increased food intake in the first hour (galanin $3 \mathrm{nmol}, 2 \pm 0.4 \mathrm{~g}$ vs saline, $0.8 \pm 0.2 \mathrm{~g}, P<0.05)$, thereafter its effect waned. Orexin-A increased food intake at 1,2 and $4 \mathrm{~h}(1 \mathrm{~h}$ food intake: orexin-A, $2.2 \pm 0.4 \mathrm{~g}$ vs saline, $0.8 \pm 0.2 \mathrm{~g}, P=0.01,2 \mathrm{~h}$ food intake: orexin-A, $3.0 \pm 0.5 \mathrm{~g}$ vs saline, $P=0.01)$. Orexin-B increased food intake at $2 \mathrm{~h}$ (orexin-B, 2.4 $\pm 0.3 \mathrm{~g}$ vs saline, $1.3 \pm 0.2 \mathrm{~g}, P<0.05$ ), this effect just failed to reach significance at 1 and $4 \mathrm{~h}$. There was no significant difference between the effect of orexin-A, orexin-B and galanin at any time-point, but all were significantly less potent than NPY at all time-points $(P<0.001)$. Orexin-A tended to stimulate food intake greater than orexin-B but this was not statistically significant.

\section{Study 2 Effect of orexin-A on c-fos expression}

ICV infusion of orexin-A greatly increased expression of $c$-fos in the PVN and arcuate nuclei and less so in the VMH. In the PVN the amount of $c$-fos expressed in response to orexin-A was $313 \%$ of control (orexin-A, $475 \pm 43$ positive nuclei per section vs saline, $152 \pm 40, P<0.005$ ) (Figs $2 \mathrm{~A}, \mathrm{~B}$ and 3 ). In the arcuate nucleus the amount of $c$-fos expressed in response to orexin-A was $293 \%$ of control (orexin-A, $211 \pm 29$ vs saline $72 \pm 7, P<0.005$ ) (Figs 2C, D and 3). In the VMH the amount of $c$-fos expressed in response to orexin-A was $158 \%$ of control (orexin-A, $127 \pm 14$ vs saline $80 \pm 11, P<0.05$ ) (Figs $2 \mathrm{C}$, D and $3)$.

Study 3 Effect of IPVN orexin-A and NPY on food intake in the early light phase

IPVN NPY significantly increased $2 \mathrm{~h}$ food intake compared 

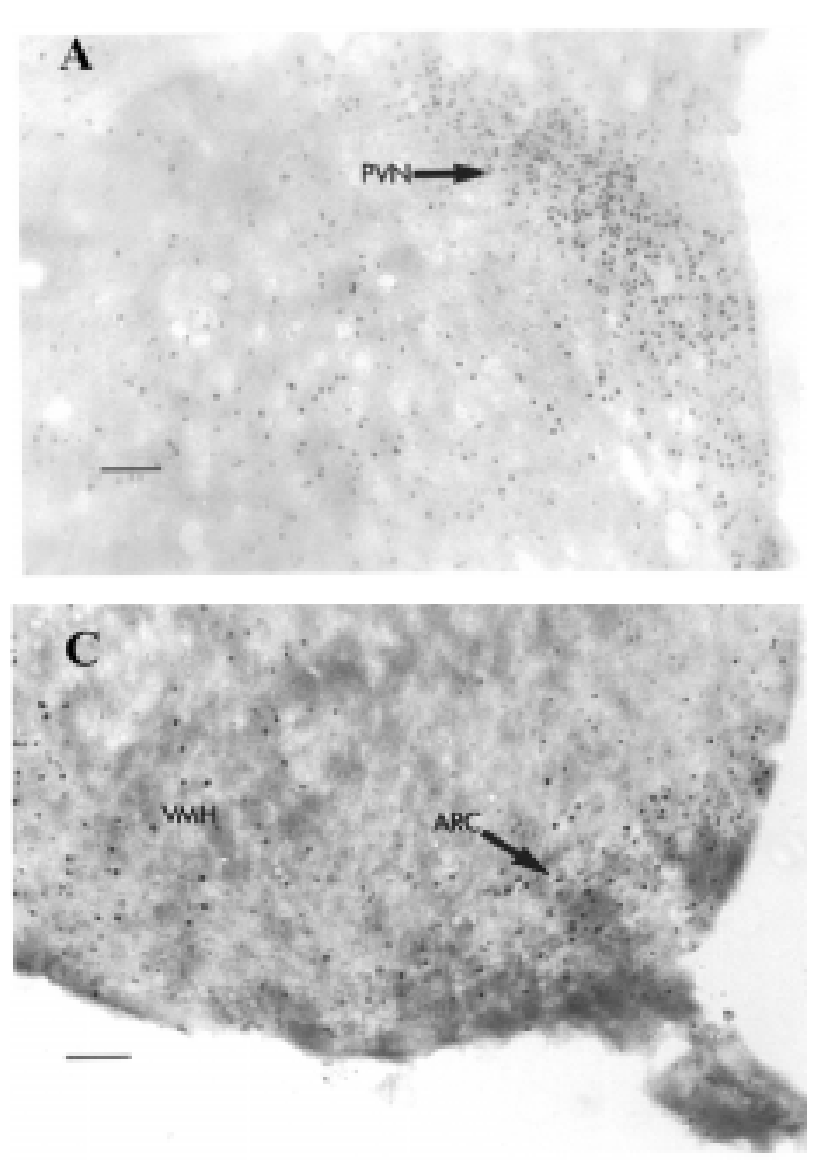
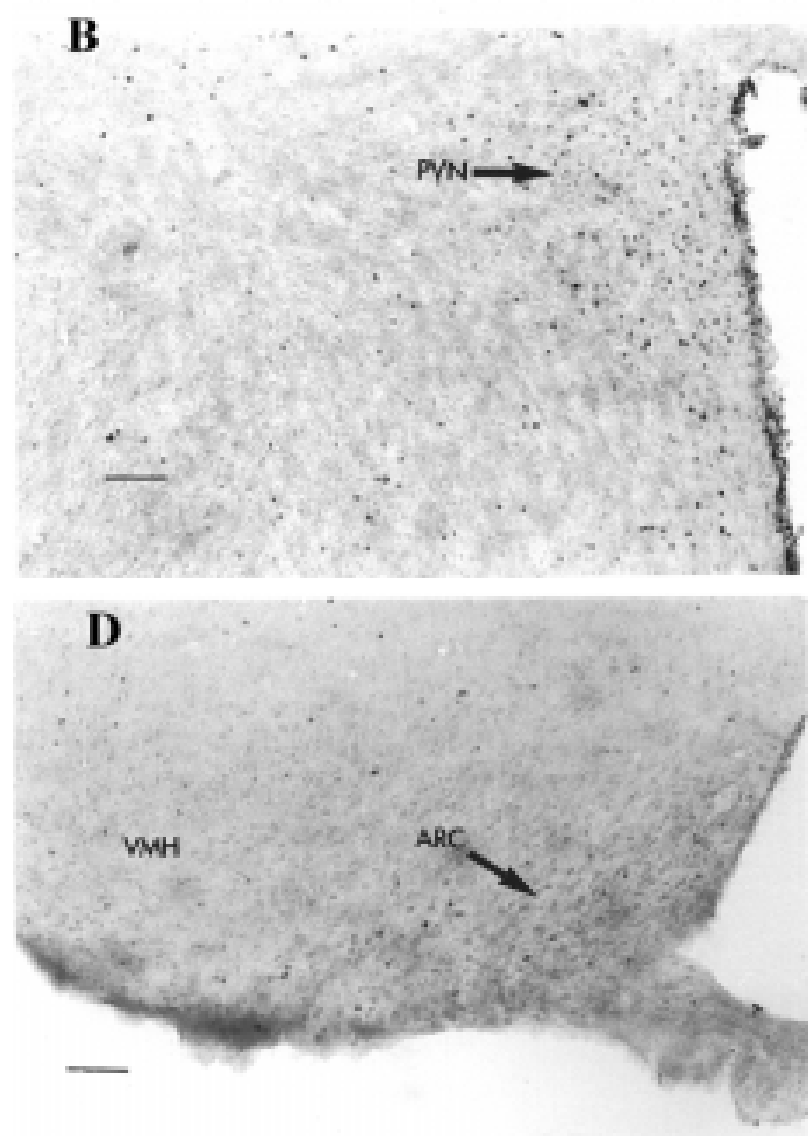

Figure 2 The expression of $c$-fos in representative coronal brain sections from the PVN (A and B), and the arcuate nucleus (ARC) and $\mathrm{VMH}(C$ and $D)$. Rats were infused with $3 \mathrm{nmol}$ orexin-A (A and C), or saline (B and D). Scale bars represent $100 \mu \mathrm{m}$.

with control (NPY 0.3nmol, $4.4 \pm 0.6 \mathrm{~g}$ vs saline, $0.9 \pm 0.2 \mathrm{~g}$, $P<0.001$ ) (Fig. 4, upper panel). Thus, the animals responded to an orexigenic agent administered IPVN. IPVN orexin-A significantly increased food intake at both 2 and $4 \mathrm{~h}$ compared with control ( $2 \mathrm{~h}$ food intake, orexin-A $0.03 \mathrm{nmol}, 1.6 \pm 0.3 \mathrm{~g}$ vs saline $0.5 \pm 0.3 \mathrm{~g}, P<0.005$ ) (Fig. 4 , lower panel). There was no greater increase in food intake with a higher dose of orexin-A ( $2 \mathrm{~h}$ food intake, orexin-A $0.3 \mathrm{nmol}, 1.4 \pm 0.3 \mathrm{~g}$ vs orexin-A $0.03 \mathrm{nmol}, 1.6 \pm 0.3 \mathrm{~g}, P=0.64)$.

\section{Discussion}

Recently, it has been suggested that orexin-A and orexin-B are physiological mediators of appetite regulation (Sakurai et al. 1998). We have undertaken studies to compare the effects of both peptides with established stimulants of food intake. NPY is the most powerful orexigenic agent known, potently stimulating feeding, and capable of causing an increase in body weight (Stanley et al. 1986). $\mathrm{MCH}$ is a more recently discovered stimulant of feeding (Qu et al. 1996). The MCH knockout mouse has a reduced weight compared to wild-type controls, demonstrating an important physiological role for this peptide in body weight regulation in the mouse (Shimada et al. 1998). Galanin is less effective and shorter acting than NPY, but nevertheless has been established as an important food intake modulator (Tempel et al. 1988).

We initially attempted to produce a dose response curve comparing the effects of orexin-A and orexin-B with saline, but this pilot data demonstrated no significant effect. This was probably due to the large number of experimental groups and the small effect of orexins on food intake (data not shown). As it appeared that the orexins were not powerful orexigenic agents, we compared their effect with established orexigenic peptides.

Orexin-B was administered up to a dose of $30 \mathrm{nmol}$, the maximum dose examined in the published report on orexins (Sakurai et al. 1998). The orexigenic effect of orexin-B was compared with NPY and MCH, the latter two were given at much lower doses, though doses that stimulate food intake in our hands (O'Shea et al. 1996, Rossi et al. 1996). Orexin-B tended to increase food intake at high dose, however, both NPY and MCH did significantly increase food intake. NPY 


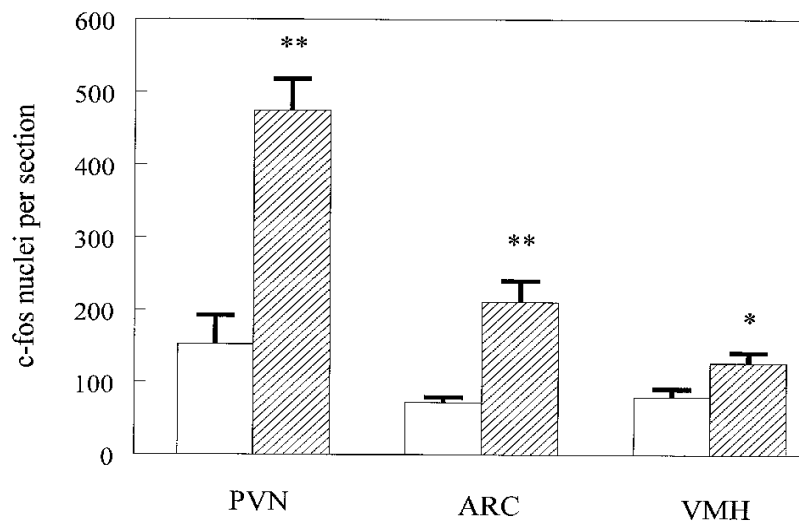

Figure 3 The number of $c$-fos positive neurons in the PVN, arcuate nucleus, and VMH following ICV orexin-A (hatched bar) or saline (open bar). ${ }^{*} P<0.05,{ }^{* *} P<0.005$ vs saline.

was significantly more effective than orexin-B, and $\mathrm{MCH}$ also appeared to be a more powerful orexigenic agent than orexin$\mathrm{B}$, even when the latter was administered at ten times the molar concentration.

Orexin-A is thought to be more effective than orexin-B (Sakurai et al. 1998). We compared the effects of orexin-A and orexin-B, at doses at which they have been shown to stimulate food intake (Sakurai et al. 1998), with NPY and galanin. Both orexin-A and orexin-B caused a small increase in food intake, however, again this was significantly less than with NPY. The orexigenic effect of galanin only lasts for one hour (Kyrkouli et al. 1986). There was no difference between the orexigenic effect of galanin and the orexins over this time period. OrexinB significantly stimulated food intake in this study, which was only a trend in the previous study, however, there was no significant difference between the effects of the synthesised and commercially produced orexin-B.

The distribution of orexin receptors has not so far been reported, although they are expressed in the brain (Sakurai et al. 1998). We investigated at what central nervous system sites the orexins induce neuronal activation. We injected orexin-A and found a highly significant and substantial stimulation of expression of the immediate early gene, $c-f o s$, in two hypothalamic areas, the PVN and arcuate nucleus. There was also a significant though smaller increase in $c$-fos in the VMH. The PVN is well known to be an important area in the regulation of food intake and is the major site of action of many orexigenic agents including NPY (Stanley et al. 1984) and galanin (Tempel et al. 1988). The arcuate nucleus and PVN are the major sources of expression of endogenous NPY (Chronwall et al. 1985). The VMH is an area also important in the regulation of food intake particularly since its destruction by lesioning causes obesity (Bray 1984).

The orexigenic effect we demonstrated with ICV orexins was weak and only just statistically significant. Since many neurons were being activated in the PVN by injection of
orexin-A, and a number of orexigenic peptides act at this site, we injected directly into the PVN to determine whether this might be a more sensitive area for the orexigenic effect of orexin-A. NPY significantly increased food intake. Orexin-A did stimulate food intake though poorly and apparently not to the same extent as ICV orexin-A. The maximum effect occurred at just $0.03 \mathrm{nmol}$. In common with other studies using the expression of immediate early genes such as $c$-fos to map the central actions of peptides (Herbert 1983), orexin-A may not have a direct action on either the PVN or arcuate nucleus but on a remote primary site that acts secondarily upon these areas.

Thus, our data appears to indicate that orexin-A and orexin-B are considerably less potent orexigenic agents than NPY, and probably less than $\mathrm{MCH}$, although not significantly different from $\mathrm{MCH}$ or galanin. Indeed, orexin-B failed to stimulate feeding significantly on occasions. Substantial
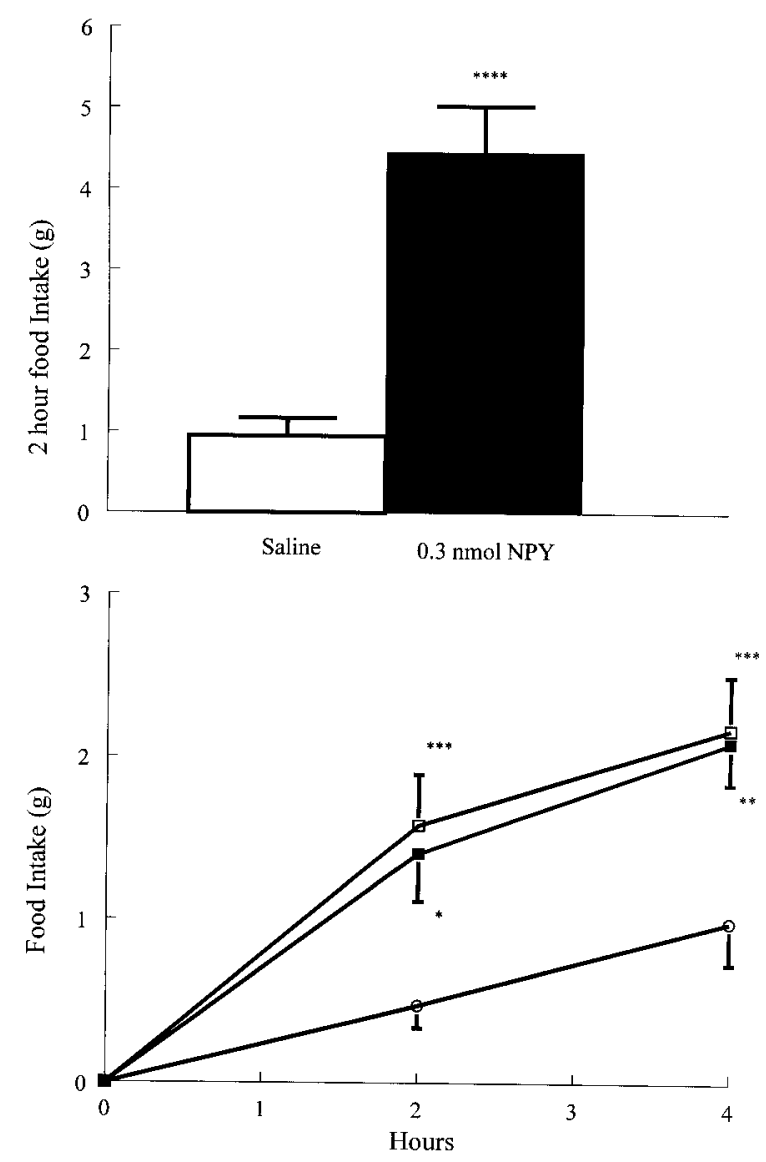

Figure 4 Effect of orexin-A and NPY on food intake when administered IPVN to Wistar rats in the early light phase. Upper panel, $0.3 \mathrm{nmol}$ NPY (solid bar), and saline (open bar), $n=12-13$ per group. Lower panel, $0.03 \mathrm{nmol}$ orexin-A ( $\square$ ), $0.3 \mathrm{nmol}$ orexin-A $(\boldsymbol{\square})$ and saline control $(O) . n=15-16$ per group. ${ }^{*} P<0.05,{ }^{* *} P<0.01,{ }^{* *} P<0.005,{ }^{* * * *} P<0.001$ vs saline. 
induction of neuronal activation occurs in the PVN and arcuate nucleus after injection of orexin-A. Orexin-A injected directly into the PVN stimulates food intake, although this effect is not powerful. The PVN may not be the primary site of action of the orexins in their orexigenic role, though the orexins may perform some other role via the PVN. Stimulation of $c$-fos expression in the arcuate nucleus might suggest an interaction between the orexins and NPY. Studies examining this would be of interest.

Before the position of the orexins in the appetite regulation hierarchy can be ascertained, further studies examining the effects of chronic injection and the interactions with known appetite regulatory peptides are required. Our data tends to indicate that the orexins are not powerful orexigenic agents in the rat. The potent up-regulation of prepro-orexin with fasting and the substantial increase in $c$-fos expression in the PVN and arcuate nuclei, particularly in response to orexin-A, combined with the small effect on food intake, imply that this is not the major physiological role of the orexins. We await characterisation of the receptor(s) and development of antagonists to assess the most important role for these peptides.

\section{Acknowledgements}

CMBE is a British Diabetic Association RD Lawrence research fellow. DS and KM are Medical Research Council students.

\section{References}

Arnold FJL, deLucas Bueno M, Shiers HM, Hancock DE, Evans GI \& Herbert J 1992 Expression of $c$-fos in regions of the basal limbic forebrain following intra-cerebroventricular corticotropinreleasing factor $(\mathrm{CRF})$ in unstressed or stressed male rats. Neuroscience $\mathbf{5 1}$ 377-390.

Bray GA 1984 Hypothalamic and genetic obesity: an appraisal of the autonomic hypothesis and the endocrine hypothesis. International Journal of Obesity 8 119-137.

Chronwall BM, DiMaggio DA, Massari VJ, Pickel VM, Ruggiero DA \& O'Donohue TL 1985 The anatomy of neuropeptide-Ycontaining neurons in rat brain. Neuroscience 15 1159-1181.

De-Lecea L, Kilduff TS, Peyron C, Gao X, Foye PE, Danielson PE, Fukuhara C, Battenberg EL, Gautvik VT, Bartlett II FS, Frankel WN, van-den-Pol AN, Bloom FE, Gautvik KM \& Sutcliffe JG 1998 The hypocretins: hypothalamus-specific peptides with neuroexcitatory activity. Proceedings of the National Academy of Sciences of the USA 95 322-327.

Herbert J 1993 Peptides in the limbic system: neurochemical codes for co-ordinated adaptive responses to behavioural and physiological demand. Progress in Neurobiology 41 723-791.
Kyrkouli SE, Stanley BG \& Leibowitz SF 1986 Galanin: stimulation of feeding by medial hypothalamic injection of this novel peptide. European Journal of Pharmacology 122 159-160.

Lambert PD, Phillips PJ, Wilding JPH, Bloom SR \& Herbert J 1995 cfos expression in the paraventricular nucleus of the hypothalamus following intracerebroventricular infusions of neuropeptide Y. Brain Research 670 59-65.

McMahon LR \& Wellman PJ 1998 PVN infusion of GLP-1-(7-36) amide suppresses feeding but does not induce aversion or alter locomotion in rats. American Journal of Physiology 274 R23-R29.

O'Shea D, Morgan DG, Meeran K, Edwards CMB, Turton MD, Choi SJ, Heath MM, Gunn I, Taylor GM, Howard JK, Bloom CI, Small CJ, Haddo O, Ma JJ, Callinan W, Smith DM, Ghatei MA \& Bloom SR 1997 Neuropeptide Y induced feeding in the rat is mediated by a novel receptor. Endocrinology 138 196-202.

Qu D, Ludwig DS, Gammeltoft S, Piper M, Pelleymounter MA, Cullen MJ, Mathes WF, Przypek R, Kanarek R \& Maratos-Flier E 1996 A role for melanin-concentrating hormone in the central regulation of feeding behaviour. Nature 380 243-247.

Rossi M, Choi SJ, O'Shea D, Miyoshi T, Ghatei MA \& Bloom SR 1997 Melanin-concentrating hormone acutely stimulates feeding, but chronic administration has no effect on body weight. Endocrinology 138 351-355.

Sagar SM, Sharp FR \& Curran T 1988 Expression of c-fos protein in brain: metabolic mapping at the cellular level. Science $\mathbf{2 4 0}$ 1328-1331

Sakurai T, Amemiya A, Ishii M, Matsuzaki I, Chemelli RM, Tanaka H, Williams SC, Richardson JA, Kozlowski GP, Wilson S, Arch JR, Buckingham RE, Haynes AC, Carr SA, Annan RS, McNulty DE, Liu WS, Terrett JA, Elshourbagy NA, Bergsma DJ \& Yanagisawa M 1998 Orexins and orexin receptors: a family of hypothalamic neuropeptides and $\mathrm{G}$ protein-coupled receptors that regulate feeding behavior. Cell 92 573-585.

Shimada M, Tritos NA, Lowell BB, Flier JS \& Maratos-Flier E 1998 Mice lacking melanin-concentrating hormone are hypophagic and lean. Nature 396 670-674.

Stanley BG \& Leibowitz SF 1984 Neuropeptide Y: stimulation of feeding and drinking by injection into the paraventricular nucleus. Life Sciences 35 2635-2642.

Stanley BG, Kyrkouli SE, Lampert S \& Leibowitz SF 1986 Neuropeptide Y chronically injected into the hypothalamus: a powerful neurochemical inducer of hyperphagia and obesity. Peptides 7 1189-1192.

Tacha DE \& McKinney LA 1992 Casein reduces nonspecific background staining in immunolabeling techniques. Journal of Histotechnology 15 127-132.

Tempel DL, Leibowitz KJ \& Leibowitz SF 1988 Effects of PVN galanin on macronutrient selection. Peptides 9 309-314.

Turton MD, O'Shea D, Gunn I, Beak SA, Edwards CMB, Meeran K, Choi SJ, Taylor GM, Heath MM, Lambert PD, Wilding JPH, Smith DM, Ghatei MA, Herbert J \& Bloom SR 1996 A role for glucagon-like peptide-1 in the central regulation of feeding. Nature 379 69-72 